\title{
Maternal Age, the Disparity across Regions and Their Correlation to Sudden Infant Death Syndrome in Taiwan: A Nationwide Cohort Study
}

\author{
Lin-Yi Huang ${ }^{1,+}$, Wan-Ju Chen ${ }^{1,+}$, Yung-Ning Yang ${ }^{1,2} \oplus$, Chien-Yi Wu ${ }^{1,2} \oplus$, Pei-Ling Wu ${ }^{1,2}$, Shu-Leei Tey ${ }^{1,2}$, \\ San-Nan Yang ${ }^{1,2}$ and Hsien-Kuan Liu ${ }^{1,2, *(D)}$ \\ 1 Department of Pediatrics, E-DA Hospital, Kaohsiung 82445, Taiwan; pedptch05680@gmail.com (L.-Y.H.); \\ ru74225@hotmail.com (W.-J.C.); ancaly@yahoo.com.tw (Y.-N.Y.); wucyi1228@yahoo.com.tw (C.-Y.W.); \\ peiling0420@gmail.com (P.-L.W.); djsr2000@hotmail.com (S.-L.T.); y520729@gmail.com (S.-N.Y.) \\ 2 College of Medicine, I-Shou University, Kaohsiung 82445, Taiwan \\ * Correspondence: hkleda0608@gmail.com; Tel.: +886-978060068 \\ + These authors have contributed equally to this work and share first authorship.
}

check for updates

Citation: Huang, L.-Y.; Chen, W.-J.; Yang, Y.-N.; Wu, C.-Y.; Wu, P.-L.; Tey, S.-L.; Yang, S.-N.; Liu, H.-K. Maternal Age, the Disparity across Regions and Their Correlation to Sudden Infant Death Syndrome in Taiwan: A Nationwide Cohort Study. Children 2021, 8, 771. https://doi.org/ 10.3390 /children 8090771

Academic Editor: Avram Denburg

Received: 22 July 2021

Accepted: 31 August 2021

Published: 1 September 2021

Publisher's Note: MDPI stays neutral with regard to jurisdictional claims in published maps and institutional affiliations.

Copyright: (c) 2021 by the authors. Licensee MDPI, Basel, Switzerland. This article is an open access article distributed under the terms and conditions of the Creative Commons Attribution (CC BY) license (https:// creativecommons.org/licenses/by/ $4.0 /)$.

\begin{abstract}
Sudden infant death syndrome (SIDS) has always been a regrettable issue for families. After sleeping in the supine position was proposed, the incidence of SIDS declined dramatically worldwide. However, SIDS still accounts for the top 10 causes of infant deaths in Taiwan. Recognizing the risk factors and attempting to minimize these cases are imperative. We obtained information on cases with SIDS from the National Health Insurance Research Database in Taiwan and interconnected it with the Taiwan Maternal and Child Health Database to acquire infant-maternal basal characteristics between 2004 and 2017. The SIDS subjects were matched 1:10 considering gestational age to normal infants. After case selection, a total of 953 SIDS cases were included. Compared with healthy infants, SIDS infants had younger parents, lower birth weight, and lower Apgar scores. After adjusting for potential confounders, infants with mothers aged $<20$ years had 2.81 times higher risk of SIDS. Moreover, infants in the non-eastern region had a significantly lower risk of SIDS than those in the eastern region. We concluded that infants of young mothers (especially maternal age $<20$ years) and infants in the eastern region of Taiwan had a higher risk of SIDS than their counterparts.
\end{abstract}

Keywords: foreign immigrant; foreign spouse; maternal age; region inequality; sudden infant death syndrome; teenage pregnancy

\section{Introduction}

Sudden infant death syndrome (SIDS) is defined as the unexpected death of babies younger than 12 months of age without any adequate cause of death even after a thorough examination and clinical history review [1-3]. To date, many studies have identified the relevant risk factors associated with SIDS. Intrinsic factors (i.e., genetics, smoke exposure, prematurity, restricted intrauterine growth), extrinsic factors (i.e., prone or side sleeping position, bed-sharing), ambient heat, and air pollution were all proposed to be relevant risks factors for SIDS [1,4-8]. Among these factors, sleeping in the prone or side-lying position is the most recognized factor that leads to SIDS [1,9]. Since the recommendation of the sleeping position policy in 1992 by the American Academy of Pediatrics, the incidence of SIDS has declined dramatically [10]. While there are many medical factors correlated with SIDS, some public health factors have also been considered. Among the public health issues, pregnancy at an early age and regional inequality of development and medical resources are essential factors that need to be investigated in Taiwan.

Young maternal age has been shown to increase the risk of SIDS, according to previous studies [11,12]. Despite the decrease in the incidence of childbirth by adolescents and the advancement of health education as a result of socioeconomic progress, there was still a 
portion of young-age pregnancies in Taiwan [13]. Teenage pregnancy has been consistently associated with a higher incidence of SIDS. This was due to illegal substance abuse, mental disorders, socioeconomic disadvantage, high incidence of developing anemia during pregnancy, preterm delivery, and delivery of low birth-weight babies [14-16]. Therefore, the relationship between SIDS and teenage pregnancy in Taiwan should be evaluated.

Furthermore, the distribution of medical resources remains unequal in Taiwan. The number of medical centers differed between urban cities and rural regions, especially shortage in the eastern area. The shortage of medical staff in the outer areas of Taiwan is also a vital issue $[17,18]$. There have also been reports that the infant mortality rate is higher in rural areas than in urban areas [19-21]. As explained earlier, since medical resources and accessibility were unequal in Taiwan, the incidence of SIDS in different areas is worth exploring.

Due to the customs and culture, parents in Taiwan are usually unwilling to perform post-mortem examination. The diagnosis of SIDS mainly made by pediatricians' judgement after thoroughly history taking and examinations among all regions in Taiwan. Furthermore, since the numbers of SIDS cases are relatively small regardless of the hospital, gathering all SIDS cases for advanced analysis might help us understanding the situation in Taiwan. To bridge these gaps due to lack of sufficient reports on the issue, we designed a study to investigate the relationship between SIDS, maternal age, and geographic distribution. This study aimed to determine the incidence of SIDS and other associated factors that could further help improving public health in Taiwan.

\section{Materials and Methods}

\subsection{Data Source}

The healthcare system in Taiwan, which is known as National Health Insurance (NHI), implemented in 1995, is a compulsory social insurance program. This system has the advantage of good accessibility and consists of a total population of over $99 \%$. The National Health Insurance Research Database (NHIRD), derived from NHI, can be analyzed for records of public health research [22-24]. The death registration database (which was initiated in 1997) was accessed from the NHIRD, and the age of death, cause of death (using the definition from the International Classification of Diseases [ICD]), and place of death were recorded [25].

The Birth Certificate Application (BCA), which was developed by the Ministry of Health and Welfare in Taiwan, contains information about birth conditions. Medical facilities have to register birth information of all newborns within 7 days of birth [26]. The registered data in BCA contained the parents' and newborns' basal characteristics, such as birth weight, gestational age, sex, mode of delivery, and age of parents. However, since each individual's death is shown in the NHIRD while the birth characteristics are registered in the BCA, gathering these data for analysis remains challenging.

To investigate the correlation between newborns who died and their birth conditions and basal characteristics, the Taiwan Maternal and Child Health Database (TMCHD), which was authorized by the Ministry of Health and Welfare, was set up to integrate these data from 2004 [27]. Hence, using the TMCHD system, we could connect and acquire information about the offspring and their parents for further analysis. The individual data in the TMCHD were all de-identified, and the requirement for informed consent was waived. We obtained approval from the Institutional Review Board of E-Da Hospital (EMRP-108-061).

\subsection{Study Population}

Infants younger than 1 year who had sudden deaths between 2004 and 2017 and whose diagnostic codes were recorded as ICD-9-CM 798.0 and ICD-10-CM R95 from the NHIRD were selected as SIDS subjects. The date of birth was used as the index day in this cohort. All subjects were observed until death or 1 year after the index day. The identities of the nonSIDS subjects were concealed for at least 1 year during the follow-up period. Cases of twins 
or multiple births, congenital abnormalities, stillbirth, deaths during the first day after birth, and patients aged $\geq 1$ year before death were excluded. The SIDS subjects were matched 1:10 to normal infants with respect to gestational age. Demographic data such as mother's age, father's age, sex of the infant, mother's nationality, birth weight, mode of delivery, Apgar score (at 1 and $5 \mathrm{~min}$ ), maternal and obstetric risk factors (anemia and hypertensive disorder, premature rupture of membranes, and fetal distress) were collected for further adjustment. The two cohorts were pooled to explore the association of maternal age at pregnancy on sudden infant death. The mothers' age at pregnancy was used as a standard to divide the subjects into two groups of "maternal age $<20$ " and "maternal age $\geq 20$ " following the definition of teenage pregnancy or adolescent pregnancy [28]. Furthermore, we divided Taiwan into separate areas for analysis according to the geographical location and regional inequality of development and medical resources [29]. This method helped to analyze the basic data of the two groups. Sudden deaths in the two groups were also selected for in-depth analysis.

\subsection{Survival Data}

The data from the national death registry maintained by the Ministry of Health and Welfare of Taiwan for cases caused by related diseases were also considered. They were used to confirm the survival of each case in the two cohort populations in this study.

\subsection{Statistical Analysis}

All data management and hazard ratio (HR) calculations were performed using the Statistical Analysis System (SAS) software for Windows (version 9.4; SAS Institute, Cary, NC, USA). Proportions were used to represent categorical variables and means \pm standard deviations were used for continuous variables. The unpaired Student's $t$-test (for continuous variables) and the chi-square test (for categorical variables) were used to compare variables between the two groups. The proportion of survival of newborns between the mothers aged $<$ or $\geq 20$ years was assessed using the Kaplan-Meier analysis, and the significance was calculated using the log-rank test. All $p$ values less than 0.05 were considered significant.

\section{Results}

Between 2004 and 2017, a total of 1915 infants diagnosed with SIDS were identified from the death registration database of the NHIRD. Since SIDS was defined as death before 1 year of age, infants born before 2004 were excluded $(n=725)$. The deaths that occurred during the perinatal period but coded with 798.0 (ICD 9) and R95 (ICD 10) $(n=2)$ were also excluded. Cases of twins or multiple births $(n=101)$, congenital abnormalities $(n=0)$, and patients aged $\geq 1$ year before death $(n=134)$ were excluded. After exclusion, 953 patients with SIDS were enrolled. Furthermore, 9530 healthy subjects were randomly recruited for comparison with the 953 SIDS infants (Figure 1). The total incidence of SIDS declined gradually during the study period $(0.54 \%$ in 2004 and $0.109 \%$ in 2017) (Figure 2). Since prematurity is a significant factor that correlates with SIDS [30], we designed a model with the same gestational age to eliminate the effect of SIDS. We also designed the model with 10 times more healthy infants than SIDS infants and compared them as shown in Table 1. Among the SIDS group, the birth weight was less $(2842.78 \pm 638.06$ and $2913.5 \pm 658.04 \mathrm{~g}$ for SIDS and healthy infants, respectively; $p<0.05$ ). A higher proportion of mothers were native citizens (Taiwanese) in the SIDS group, and the age of the parents was less than that of those of healthy infants. The SIDS group also showed lower Apgar scores at $1 \mathrm{~min}$ and $5 \mathrm{~min}$ (all $p<0.001$ ) and a higher incidence of fetal distress during the perinatal period $(p<0.05)$. The incidence of SIDS also showed difference between regions in Taiwan $(p<0.05)$. The data showed no significant difference in other maternal and obstetric risk factors, such as maternal anemia and hypertensive disorders. In contrast, the incidence of premature rupture of membranes was higher in the healthy infant cohort $(p<0.05)$. 


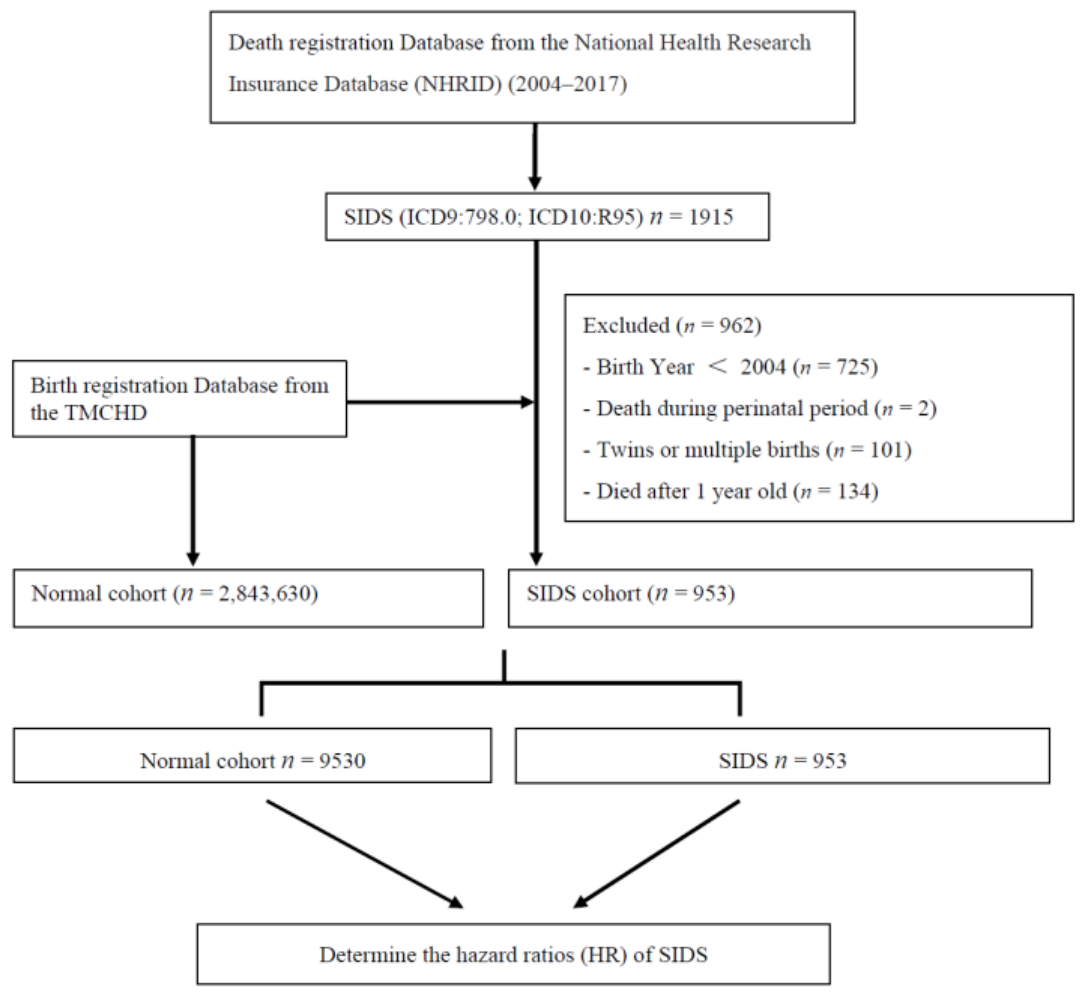

Figure 1. Study flowchart.

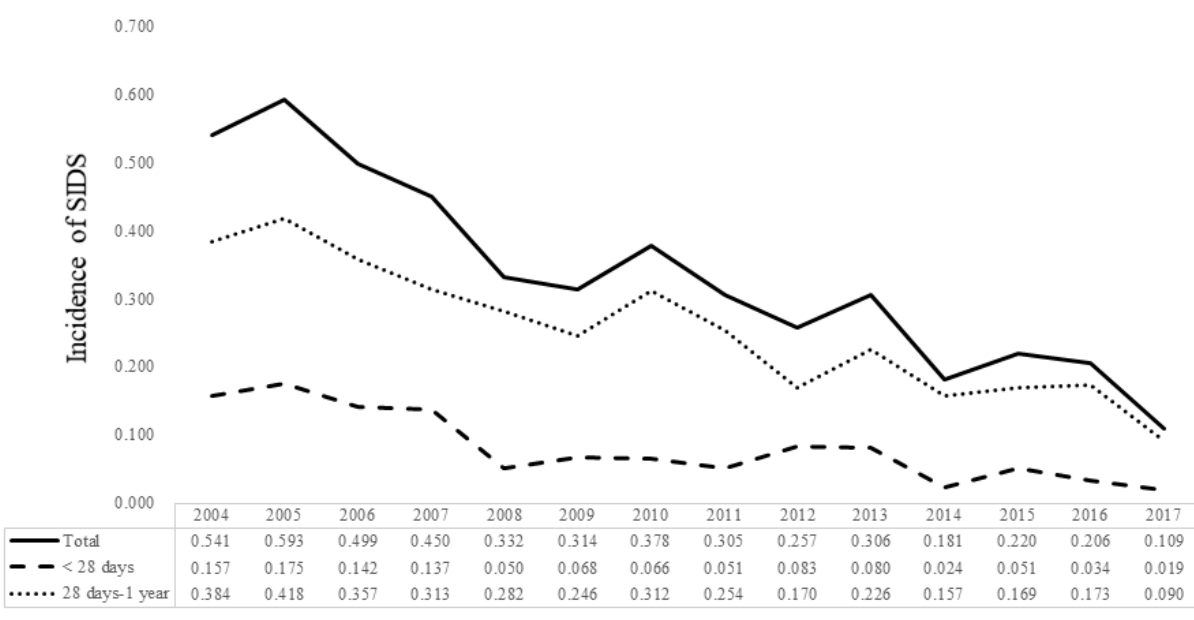

Years

\begin{tabular}{|c|c|c|c|c|c|c|c|c|c|c|c|c|c|c|}
\hline Year & 2004 & 2005 & 2006 & 2007 & 2008 & 2009 & 2010 & 2011 & 2012 & 2013 & 2014 & 2015 & 2016 & 2017 \\
\hline $\begin{array}{l}\text { Total } \\
\text { population }\end{array}$ & 216,419 & 205,854 & 204,459 & 204,414 & 198,733 & 191,310 & 166,886 & 196,627 & 229,481 & 199,113 & 210,383 & 213,598 & 208,440 & 210,181 \\
\hline SIDS & 117 & 122 & 102 & 92 & 66 & 60 & 63 & 60 & 59 & 61 & 38 & 47 & 43 & 23 \\
\hline Incidence (\%o) & 0.541 & 0.593 & 0.499 & 0.450 & 0.332 & 0.314 & 0.378 & 0.305 & 0.257 & 0.306 & 0.181 & 0.220 & 0.206 & 0.109 \\
\hline Before 28days & 34 & 36 & 29 & 28 & 10 & 13 & 11 & 10 & 19 & 16 & 5 & 11 & 7 & 4 \\
\hline Incidence (\%) & 0.157 & 0.175 & 0.142 & 0.137 & 0.050 & 0.068 & 0.066 & 0.051 & 0.083 & 0.080 & 0.024 & 0.051 & 0.034 & 0.019 \\
\hline 28 days-1 year & 83 & 86 & 73 & 64 & 56 & 47 & 52 & 50 & 39 & 45 & 33 & 36 & 36 & 19 \\
\hline Incidence (\%o) & 0.384 & 0.418 & 0.357 & 0.313 & 0.282 & 0.246 & 0.312 & 0.254 & 0.170 & 0.226 & 0.157 & 0.169 & 0.173 & 0.090 \\
\hline
\end{tabular}

Figure 2. Sudden infant death syndrome (SIDS) population and the incidence of SIDS in Taiwan between 2004 to 2017. 
Table 1. Baseline characteristics of the study population coded with SIDS, Taiwan, 2004-2017.

\begin{tabular}{|c|c|c|c|}
\hline & $\begin{array}{l}\text { Normal Cohort } \\
\quad n=9530\end{array}$ & $\begin{array}{l}\text { SIDS Cohort } \\
\quad n=953\end{array}$ & $p$-Value \\
\hline Gestational age & $37.34 \pm 3.31$ & $37.34 \pm 3.31$ & $>0.9999$ \\
\hline Infant sex & & & 0.0013 \\
\hline Boy & $4911(51.53 \%)$ & $543(56.98 \%)$ & \\
\hline Girl & 4619 (48.47\%) & $410(43.02 \%)$ & \\
\hline Birth weight & $2913.5 \pm 658.04$ & $2842.78 \pm 638.06$ & 0.0015 \\
\hline Native citizen (mother) & $8744(91.75 \%)$ & $913(95.8 \%)$ & $<0.0001$ \\
\hline Age of father & $33.84 \pm 5.49$ & $32.8 \pm 6.10$ & $<0.0001$ \\
\hline Age of mother & $30.73 \pm 5.03$ & $28.18 \pm 5.87$ & $<0.0001$ \\
\hline Region (in Taiwan) & & & 0.0039 \\
\hline Northern & $2869(30.1 \%)$ & $249(26.13 \%)$ & \\
\hline North Central & $1761(18.48 \%)$ & $213(22.35 \%)$ & \\
\hline Central & $1908(20.02 \%)$ & $181(18.99 \%)$ & \\
\hline South Central & $1238(12.99 \%)$ & $123(12.91 \%)$ & \\
\hline Southern & $1409(14.78 \%)$ & $138(14.48 \%)$ & \\
\hline Eastern & $345(3.62 \%)$ & $49(5.14 \%)$ & \\
\hline Mode of delivery & & & 0.0056 \\
\hline Vagina & $5813(61 \%)$ & $625(65.58 \%)$ & \\
\hline Cesarean section & 3717 (39\%) & $328(34.42 \%)$ & \\
\hline Apgar score (1 min) & $8.07 \pm 1.34$ & $7.66 \pm 1.96$ & $<0.0001$ \\
\hline Apgar score $(5 \mathrm{~min})$ & $9.84 \pm 1.27$ & $9.2 \pm 2.72$ & $<0.0001$ \\
\hline \multicolumn{4}{|l|}{ Maternal and obstetric risk factors } \\
\hline Anemia & $79(0.83 \%)$ & $6(0.63 \%)$ & 0.5129 \\
\hline Hypertensive disorder & $186(1.95 \%)$ & $15(1.57 \%)$ & 0.4175 \\
\hline Premature rupture of membranes & $285(2.99 \%)$ & $10(1.05 \%)$ & 0.0006 \\
\hline Fetal distress & $142(1.49 \%)$ & $28(2.94 \%)$ & 0.0007 \\
\hline
\end{tabular}

SIDS: Sudden infant death syndrome.

\subsection{Prediction for the Occurrence of SIDS}

After adjusting for confounding factors to predict the occurrence of SIDS, offspring of mothers younger than 20 years had a 2.81 times higher risk of sudden death than those of mothers older than 20 years. Analyzing the difference across regions, infants born in the non-eastern region rather than in the eastern region of Taiwan showed a significantly lower SIDS risk (HR: 0.42, 0.42, 0.37, 0.37, and 0.35 in the Northern, North Central, Central, South Central, and Southern areas, respectively; all $p<0.05)$. The incidence of post-natal mortality before 1 year old was shown in Supplementary Figure S1. Higher mortality rate before 1 year old in the Eastern area was also noted. A higher Apgar score at 1 min was associated with a lower risk of SIDS (HR: 0.73, $p<0.05$ ). Furthermore, younger age of fathers and lower gestational weeks were also significantly associated with SIDS (Table 2).

Table 2. Predictions for the occurrence of SIDS using multiple regression.

\begin{tabular}{|c|c|c|c|c|}
\hline & $\begin{array}{c}\text { Crude } \\
\text { HR }(95 \% \text { CI })\end{array}$ & $p$ & $\begin{array}{c}\text { Adjusted } \\
\text { HR (95\% CI) }\end{array}$ & $p$ \\
\hline $\begin{array}{c}\text { Maternal age } \\
(<20 \text { vs. } \geq 20 \text { years })\end{array}$ & $4.22(3.38-5.27)$ & $<0.0001$ & $2.81(1.43-5.50)$ & $<0.01$ \\
\hline Gender & $1.23(1.08-1.40)$ & $<0.01$ & $1.20(0.93-1.56)$ & 0.166 \\
\hline Birth weight & $1.00(1.00-1.00)$ & $<0.01$ & $1.00(1.00-1.00)$ & 0.083 \\
\hline Paternal age & $0.97(0.95-0.98)$ & $<0.0001$ & $0.96(0.94-0.99)$ & $<0.01$ \\
\hline Native citizen (mother) & $1.99(1.45-2.74)$ & $<0.0001$ & $1.78(0.90-3.50)$ & 0.095 \\
\hline \multicolumn{5}{|l|}{ Region (in Taiwan) } \\
\hline Northern & $0.62(0.46-0.84)$ & $<0.01$ & $0.42(0.20-0.88)$ & $<0.05$ \\
\hline North Central & $0.86(0.63-1.17)$ & 0.326 & $0.42(0.20-0.89)$ & $<0.05$ \\
\hline Central & $0.68(0.50-0.93)$ & $<0.05$ & $0.37(0.18-0.80)$ & $<0.05$ \\
\hline South Central & $0.71(0.51-0.99)$ & $<0.05$ & $0.37(0.17-0.82)$ & $<0.05$ \\
\hline Southern & $0.70(0.51-0.97)$ & $<0.05$ & $0.35(0.16-0.77)$ & $<0.01$ \\
\hline Eastern & REF. & & REF. & \\
\hline
\end{tabular}


Table 2. Cont.

\begin{tabular}{ccccc}
\hline & $\begin{array}{c}\text { Crude } \\
\text { HR (95\% CI) }\end{array}$ & $p$ & $\begin{array}{c}\text { Adjusted } \\
\text { HR (95\% CI) }\end{array}$ & $p$ \\
\hline Gestational age & $1.00(0.98-1.02)$ & 0.868 & $1.11(1.01-1.21)$ & $<0.05$ \\
Mode of delivery & $1.21(1.06-1.38)$ & $<0.01$ & $1.18(0.88-1.58)$ & 0.262 \\
Apgar score (1 min) & $0.85(0.82-0.88)$ & $<0.0001$ & $0.73(0.55-0.96)$ & $<0.05$ \\
Apgar score (5 min) & $0.85(0.81-0.88)$ & $<0.0001$ & $0.97(0.76-1.24)$ & 0.832 \\
Maternal and obstetric risk factors & & & & 0.910 \\
Anemia & $0.76(0.34-1.70)$ & 0.505 & $1.12(0.16-8.11)$ & 0.557 \\
Hypertensive disorder & $0.82(0.49-1.36)$ & 0.434 & $1.35(0.49-3.70)$ & 0.150 \\
Premature rupture of membranes & $0.36(0.19-0.66)$ & $<0.05$ & $0.43(0.13-1.36)$ & 0.502 \\
Fetal distress & $1.98(1.36-2.88)$ & $<0.05$ & $0.61(0.14-2.58)$ & 0.505 \\
\hline
\end{tabular}

SIDS, Sudden infant death syndrome; HR, Hazard Ratio; CI, Confidence interval. REF, reference.

3.2. Comparison of the Differences between Two Groups using 20 Years of Maternal Age as the Reference in the Total Study Population

The total study population was divided into two groups following the definition of teenage pregnancy (maternal age $<20$ years vs. maternal age $\geq 20$ years). Lower birth weight (2679.94 \pm 734.43 vs. $2913.01 \pm 653.35 \mathrm{~g})$, younger paternal age (25.19 $\pm 5.26 \mathrm{vs}$. $33.88 \pm 5.45$ years), less gestational age of neonates ( $36.56 \pm 4.43$ vs. $37.36 \pm 3.27$ weeks), lower Apgar score at $1 \mathrm{~min}(7.57 \pm 1.92$ vs. $8.04 \pm 1.39)$ and $5 \mathrm{~min}(9.12 \pm 2.86 \mathrm{vs}$ $9.79 \pm 1.42)$, and more cases of SIDS (31.84\% vs. $8.5 \%)$ were observed in the maternal age $<20$ years group than in the maternal age $\geq 20$ years group $(p<0.001$ for all the above parameters). Furthermore, the proportion of maternal anemia in the group aged $<20$ years was significantly higher than that in the group aged $\geq 20$ years (Table 3 ). In contrast, there were no differences among maternal hypertensive disorder, the proportion of premature rupture of membranes, and fetal distress episodes during the perinatal period between the two groups (Table 3).

Table 3. Basal characteristics between the two groups divided by maternal age $(<20$ and $\geq 20$ years).

\begin{tabular}{cccc}
\hline & $\begin{array}{c}\text { Age } \begin{array}{c}\mathbf{2 0} \text { Years Cohort } \\
(\boldsymbol{n}=\mathbf{2 6 7 )}\end{array} \\
\text { Age } \geq \mathbf{2 0} \text { Years Cohort } \\
(\boldsymbol{n}=\mathbf{1 0}, \mathbf{2 1 6})\end{array}$ & $p$ \\
\hline Cases of SIDS & $85(31.84 \%)$ & $868(8.50 \%)$ & $<0.0001$ \\
Birth weight & $2679.94 \pm 734.43$ & $2913.01 \pm 653.35$ & $<0.0001$ \\
Native citizen (mother) & $252(94.38 \%)$ & $9405(92.06 \%)$ & 0.1647 \\
Paternal age & $25.19 \pm 5.26$ & $33.88 \pm 5.45$ & $<0.0001$ \\
Maternal age & $18.15 \pm 1.31$ & $30.82 \pm 4.82$ & $<0.0001$ \\
Region (in Taiwan) & & & $<0.0001$ \\
Northern & $47(17.60 \%)$ & $3071(30.06 \%)$ & \\
North Central & $59(22.10 \%)$ & $1915(18.75 \%)$ & \\
Central & $56(20.97 \%)$ & $2033(19.90 \%)$ & \\
South Central & $43(16.10 \%)$ & $1318(12.90 \%)$ & \\
Southern & $42(15.73 \%)$ & $1505(14.73 \%)$ & \\
Eastern & $20(7.49 \%)$ & $374(3.66 \%)$ & 0.0001 \\
Gestational age & $36.56 \pm 4.43$ & $37.36 \pm 3.27$ & \\
Mode of delivery & $218(81.65 \%)$ & $6220(60.88 \%)$ & \\
Vagina & $49(18.35 \%)$ & $3996(39.12 \%)$ & \\
Cesarean section & $7.57 \pm 1.92$ & $8.04 \pm 1.39$ & $<0.0001$ \\
Apgar score (1 min) & $9.12 \pm 2.86$ & $9.79 \pm 1.42$ & 0.0002 \\
Apgar score (5 min) & & & \\
Maternal and obstetric risk & $7(2.62 \%)$ & $78(0.76 \%)$ & 0.0008 \\
factors & $3(1.12 \%)$ & $198(1.94 \%)$ & 0.3380 \\
Anemia & $6(2.25 \%)$ & $289(2.83 \%)$ & 0.5704 \\
Hypertensive disorder & $3(1.12 \%)$ & $167(1.63 \%)$ & 0.5139 \\
Premature rupture of & & &
\end{tabular}




\subsection{Proportion of Survival between the Maternal Age $\geq 20$ and $<20$ Years Cohorts}

The Kaplan-Meier survival curve was drawn to assess survival rate until 12 months of age according to the definition of SIDS. The curve is presented in Figure 3. The 1-year survival rate was lower in neonates of mothers aged $<20$ years (log-rank test, $p<0.0001$ ).

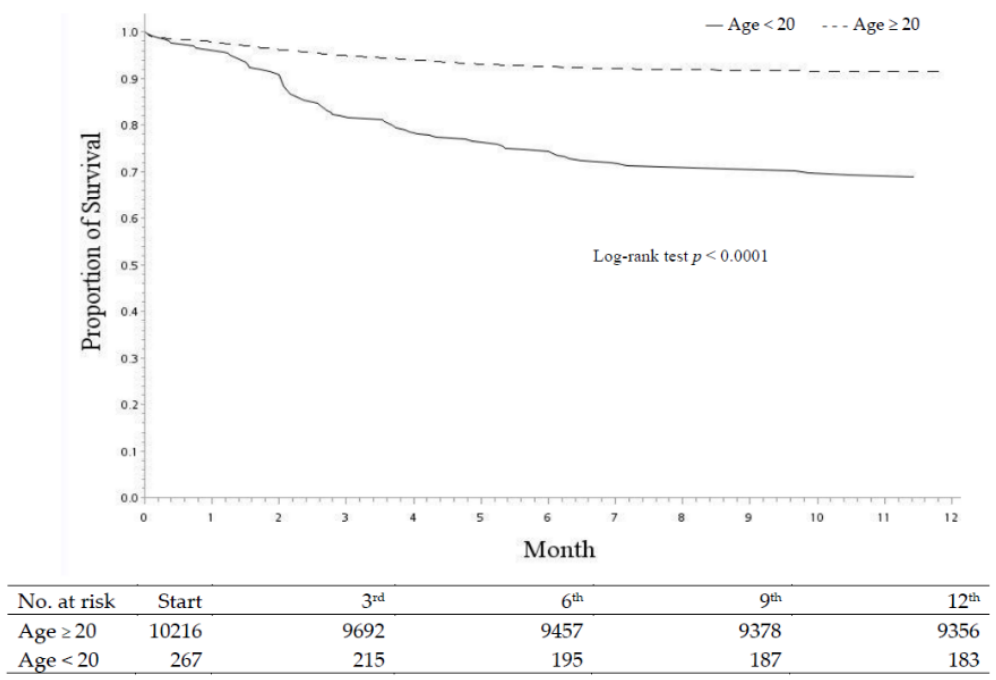

Figure 3. Proportion of survival of offspring between the maternal age $\geq 20$ and $<20$ years cohorts.

\section{Discussion}

The infant mortality rate (IMR), defined as the number of deaths of children under 1 year of age, is regarded as a basic indicator of public health worldwide [31]. IMR has gradually declined over the past decades worldwide, including Taiwan. This is owing to advancements in medical technologies, promotion of public health education, and increase in medical manpower and facilities [32,33]. Even though Taiwan was not included in the analysis of the Organization for Economic Cooperation and Development (OECD) countries, IMR still ranked moderately higher in Taiwan than in other European countries [34]. In our study, the SIDS incidence was observed to decrease from 5.41 in 10,000 children to 1.09 in 10,000 children. However, even if the rate of SIDS gradually declined, it still accounted for the top 10 causes of infant deaths [35]. Meanwhile, the trend of Taiwan's fertility rate is decreasing [36]. Under these circumstances, measures should be implemented to minimize SIDS cases.

The proportion of teen pregnancies in Taiwan remains higher than that in some European countries [37]. A local study revealed that this might be related to poor contraceptive knowledge and low socioeconomic status [38]. Moreover, teen child-bearing women are more likely to have lower educational growth, more adverse pregnancy complications, and even more postpartum depression $[39,40]$. In our study, infants of mothers aged $<20$ years had 2.81 times higher SIDS risk than those of mothers aged $\geq 20$ years. In addition, our results also suggested that infants with mothers aged $<20$ years tend to have a small gestational age, which is also a key factor associated with SIDS [1,2]. Similar to maternal age, younger paternal age was also significantly associated with higher SIDS occurrence according to our results. This might also be another social issue, which is that of young-age marriage, that we should pay attention to. These results imply that teenage pregnancies should be taken seriously. Comprehensive sex education, not only for young women but also for young men, should be promoted by the government to effectively prevent and decrease the incidence of teenage pregnancies [41,42] and, thus, decrease the incidence of SIDS.

Our results also indicated that there are notable geographic variations in the SIDS occurrence rate. The eastern region had a higher incidence of SIDS than the non-eastern region. This may be owing to the lower medical personnel density in the eastern region than 
in other regions [29]. In Taiwan, the availability, accessibility, affordability, and acceptability of medical resources were remarkable after the NHI was implemented in 1995. However, insufficient medical resources in the eastern region of Taiwan remain a significant issue [29]. Previous studies have demonstrated a disparity in SIDS incidence between urban and rural areas and in income levels. SIDS incidence was higher in rural areas and the impoverished population [21,43]. This could explain the higher SIDS occurrence in the eastern region of Taiwan. Narrowing the urban-rural and inter-regional gaps in development will play an important role in a child's health environment. The other possible reason that might lead to regional disparity is the different diagnostic approach of SIDS. In Taiwan, the public health insurance was implemented for a long time, and all the diagnostic approach was almost consistent. Furthermore, regular conferences were held to discuss about SIDS and child health care issues so that the diagnostic process goes identical. Owing to above reason, the different incidence of SIDS might not be associated with the different diagnostic approach

Moreover, previous study also revealed that the child maltreatment rate in the eastern region ranked first in Taiwan [44]. Since SIDS is a diagnosis after excluding all explainable causes, it is important to distinguish it from child maltreatment. However, SIDS is difficult to distinguish completely from fatal child abuse [45]. In Taiwan, most SIDS cases were diagnosed clinically without autopsy. However, even under autopsy, SIDS is difficult to distinguish from suffocation caused by soft objects, either accidentally or deliberately [45]. Thus, the more SIDS cases that have been reported in the eastern region might be because they were caused by child maltreatment rather than SIDS. Regardless, it remains a huge burden on society and an issue that needs to be resolved urgently.

Another result worth noting is the incidence of SIDS between native Taiwanese and immigrated mothers. The relationship between maternal mental health and offspring health has always been a topic of investigation. Previous studies showed that SIDS is tightly correlated with maternal psychiatric disorders, especially perinatal depression $[46,47]$. In Taiwan, there has been a large increase in transnational marriages from China and Southeast Asia (Vietnam and Indonesia) [48]. Many of these foreign spouses face some psychiatric disorders, especially those who cannot speak the local language, according to a previous study $[49,50]$. However, according to our results, there was no obvious difference in SIDS between native and foreign-born infants. This could be explained by the social and cultural background of foreign spouses in Taiwan. Most foreign mothers migrated from China [48]. In fact, there is no apparent discrepancy in the background culture, language, and religion between China and Taiwan. Therefore, immigrated women from China could easily merge into society without substantial effort, thus reasonably explaining our results.

This study had some limitations. First, it was a retrospective study, and data were obtained from the NHIRD based on ICD-9-CM and ICD-10-CM codes. Misclassification of diseases may occur. We could not exclude selection bias because of the retrospective nature of the study. Second, the diagnosis of SIDS in Taiwan is based on pediatricians' clinical judgement after thoroughly history taking and excluding all the possible causes. Postmortem examination in Taiwan is not routinely arranged unless the pediatrician could not make a diagnosis. In previous literature (written in Chinese), the post-mortem examination rate was only $6.03 \%$ between 1996 to 2005 [51]. However, there is a certain consensus on the diagnosis of SIDS even in various regions of Taiwan. Owing to this reason, the practices in different regions of Taiwan are roughly the same. Third, it is difficult to make a precise clinical diagnosis of SIDS. SIDS is diagnosed after excluding all reasonable causes of death. However, some hidden issues may not be found immediately while the death occurred, for example, child maltreatment. However, since the child protection medical service demonstration center was established in Taiwan in August 2014, the ability to recognize child maltreatment by medical staff has enhanced and more attention has been paid to child maltreatment [52]. Thus, the misjudgment of SIDS cases and child maltreatment has decreased. Fourth, infant death data were obtained from the NHI database. However, the maternal data of the cases were difficult to thoroughly link. Though we integrated 
these data with TMCHD, data on some maternal risk factors that would affect SIDS (i.e., gestational diabetes, smoking) could not be acquired completely.

\section{Conclusions}

In conclusion, the trend of SIDS in Taiwan gradually declined annually after more public health promotion and attached great importance to children's safety. The risk factors for SIDS analyzed using the national population data revealed that maternal age and regional distribution were the most significant factors. Offspring of younger mothers, especially of aged $<20$ years, had a higher incidence of SIDS. Infants in the non-eastern region of Taiwan, which is an area with relatively abundant medical resources and is more developed than the eastern area, had a lower risk of SIDS. Moreover, there was no discrepancy in SIDS incidence between the offspring of foreign immigrants and native mothers. Since there was no significant difference between the immigrant and native mothers, we might consider dividing the foreign spouses into China and Southeast Asia to see if there will be different results in the further study.

Supplementary Materials: The following are available online at https://www.mdpi.com/article/ 10.3390 / children8090771/s1. Figure S1. The incidence of post-natal mortality $<1$ year old between regions per 1000 live births in Taiwan (2004 to 2017).

Author Contributions: Conceptualization, H.-K.L., L.-Y.H. and W.-J.C.; Data curation, S.-L.T., L.-Y.H. and W.-J.C.; Formal analysis, Y.-N.Y., S.-L.T. and C.-Y.W.; Funding acquisition, L.-Y.H. and W.-J.C.; Investigation, P.-L.W.; Methodology, H.-K.L.; Project administration, H.-K.L.; Resources, Y.-N.Y., S.-L.T. and C.-Y.W.; Supervision, S.-N.Y. and H.-K.L.; Visualization, P.-L.W.; Writing-original draft, L.-Y.H. and W.-J.C.; Writing — review and editing, S.-N.Y., H.-K.L., W.-J.C. and C.-Y.W. All authors have read and agreed to the published version of the manuscript.

Funding: This study was supported by the intramural funding provided by the Room for Database Research, E-DA HEALTHCARE GROUP (grant EDAD1903).

Institutional Review Board Statement: The study was conducted according to the guidelines of the Declaration of Helsinki, and approved by the Institutional Review Board of E-Da Hospital (EMRP-108-061 July 2019).

Informed Consent Statement: Informed consent was waived due to all subjects were de-identified before analysis and approved by the Institutional Review Board of E-Da Hospital.

Data Availability Statement: The data presented in this study are available on request from the corresponding author. The data are not publicly available because they report private information about participants.

Acknowledgments: The authors are grateful to Health Data Science Center, National Cheng Kung University Hospital for providing administrative and technical support.

Conflicts of Interest: The authors declare no conflict of interest. The funders had no role in the design of the study; in the collection, analyses, or interpretation of data; in the writing of the manuscript, or in the decision to publish the results.

\section{References}

1. Goldberg, N.; Rodriguez-Prado, Y.; Tillery, R.; Chua, C. Sudden infant death syndrome: A review. Pediatr. Ann. 2018, 47, e118-e123. [CrossRef]

2. Hakeem, G.F.; Oddy, L.; Holcroft, C.A.; Abenhaim, H.A. Incidence and determinants of sudden infant death syndrome: A population-based study on 37 million births. World J. Pediatr. 2015, 11, 41-47. [CrossRef]

3. Kinney, H.C.; Thach, B.T. The sudden infant death syndrome. N. Engl. J. Med. 2009, 361, 795-805. [CrossRef]

4. Li, D.K.; Petitti, D.B.; Willinger, M.; McMahon, R.; Odouli, R.; Vu, H.; Hoffman, H.J. Infant sleeping position and the risk of sudden infant death syndrome in California, 1997-2000. Am. J. Epidemiol. 2003, 157, 446-455. [CrossRef]

5. Hwang, M.J.; Cheong, H.K.; Kim, J.H. Ambient air pollution and sudden infant death syndrome in Korea: A time-stratified case-crossover study. Int. J. Environ. Res. Public Health 2019, 16, 3273. [CrossRef] [PubMed]

6. Jhun, I.; Mata, D.A.; Nordio, F.; Lee, M.; Schwartz, J.; Zanobetti, A. Ambient temperature and sudden infant death syndrome in the United States. Epidemiology 2017, 28, 728-734. [CrossRef] 
7. Anderson, T.M.; Lavista Ferres, J.M.; Ren, S.Y.; Moon, R.Y.; Goldstein, R.D.; Ramirez, J.M.; Mitchell, E.A. Maternal smoking before and during pregnancy and the risk of sudden unexpected infant death. Pediatrics 2019, 143, e20183325. [CrossRef]

8. Horne, R.S.C. Sudden infant death syndrome: Current perspectives. Intern. Med. J. 2019, 49, 433-438. [CrossRef] [PubMed]

9. Vennemann, M.M.; Findeisen, M.; Butterfass-Bahloul, T.; Jorch, G.; Brinkmann, B.; Köpcke, W.; Bajanowski, T.; Mitchell, E.A.; GeSID Group. Modifiable risk factors for SIDS in Germany: Results of GeSID. Acta Paediatr. 2005, 94, 655-660. [CrossRef]

10. Moon, R.Y.; Task Force on Sudden Infant Death Syndrome. SIDS and other sleep-related infant deaths: Evidence base for 2016 updated recommendations for a safe infant sleeping environment. Pediatrics 2016, 138, e20162940. [CrossRef] [PubMed]

11. Babson, S.G.; Clarke, N.G. Relationship between infant death and maternal age. Comparison of sudden infant death incidence with other causes of infant mortality. J. Pediatr. 1983, 103, 391-393. [CrossRef]

12. Pinho, A.P.; Aerts, D.; Nunes, M.L. Risk factors for sudden infant death syndrome in a developing country. Rev. Saude Publica. 2008, 42, 396-401. [CrossRef] [PubMed]

13. Huang, C.C.; Lin, Y.C.; Huang, Y.T.; Huang, K.H. Comparison of medical issues in antenatal and perinatal periods in early youth, adolescent, and young adult mothers in Taiwan: A 10-year nationwide study. BMC Pregnancy Childbirth 2014, 14, 260. [CrossRef] [PubMed]

14. Wong, S.P.W.; Twynstra, J.; Gilliland, J.A.; Cook, J.L.; Seabrook, J.A. Risk factors and birth outcomes associated with teenage pregnancy: A Canadian sample. J. Pediatr. Adolesc. Gynecol. 2020, 33, 153-159. [CrossRef]

15. Mahavarkar, S.H.; Madhu, C.K.; Mule, V.D. A comparative study of teenage pregnancy. J. Obstet. Gynaecol. 2008, $28,604-607$. [CrossRef] [PubMed]

16. Caraballo, M.; Shimasaki, S.; Johnston, K.; Tung, G.; Albright, K.; Halbower, A.C. Knowledge, attitudes, and risk for sudden unexpected infant death in children of adolescent mothers: A qualitative study. J. Pediatr. 2016, 174, 78-83.e2. [CrossRef]

17. Kreng, V.B.; Yang, C.T. The equality of resource allocation in health care under the National Health Insurance System in Taiwan. Health Policy 2011, 100, 203-210. [CrossRef]

18. Hu, J.L.; Chang, M.C.; Chung, H.J. Projecting the target quantity of medical staff in Taiwan's administrative regions by the theory of carrying capacity. Int. J. Environ. Res. Public Health 2020, 17, 2998. [CrossRef]

19. Ely, D.M.; Hoyert, D.L. Differences between rural and urban areas in mortality rates for the leading causes of infant death: United States, 2013-2015. NCHS Data Brief 2018, 300, 1-8.

20. Womack, L.S.; Rossen, L.M.; Hirai, A.H. Urban-rural infant mortality disparities by race and ethnicity and cause of death. Am. J. Prev. Med. 2020, 58, 254-260. [CrossRef] [PubMed]

21. Mohamoud, Y.A.; Kirby, R.S.; Ehrenthal, D.B. Poverty, urban-rural classification and term infant mortality: A population-based multilevel analysis. BMC Pregnancy Childbirth 2019, 19, 40. [CrossRef]

22. Wu, T.Y.; Majeed, A.; Kuo, K.N. An overview of the healthcare system in Taiwan. Lond. J. Prim. Care 2010, 3, 115-119. [CrossRef]

23. Lu, W.L.; Shen, P.C.; Lee, C.H.; Su, Y.T.; Chen, L.M. High risk of early cataracts in young type 1 diabetes group: A nationwide cohort study. Int. J. Endocrinol. 2020, 2020, 8160256. [CrossRef]

24. Hsieh, C.Y.; Su, C.C.; Shao, S.C.; Sung, S.F.; Lin, S.J.; Kao Yang, Y.H.; Lai, E.C. Taiwan's National Health Insurance Research Database: Past and future. Clin. Epidemiol. 2019, 11, 349-358. [CrossRef]

25. Hsu, S.T.; Hsieh, C.J.; Chen, H.W.; Jeng, S.F.; Wu, H.C.; Chen, M.H.; Chen, C.Y.; Chou, H.C.; Tsao, P.N.; Chen, P.C.; et al. Nationwide birth weight and gestational age-specific neonatal mortality rate in Taiwan. Pediatr. Neonatol. 2015, 56, 149-158. [CrossRef] [PubMed]

26. Health Promotion Administration, Ministry of Health and Welfare in Taiwan. Reporting. Available online: http://www.hpa.gov. tw /English/ClassPrint.aspx?No=201502020008 (accessed on 5 May 2021).

27. Li, C.Y.; Chen, L.H.; Chiou, M.J.; Liang, F.W.; Lu, T.H. Set-up and future applications of the Taiwan Maternal and Child Health Database (TMCHD). Taiwan J. Public Health 2016, 35, 221-233.

28. Leftwich, H.K.; Alves, M.V. Adolescent pregnancy. Pediatr. Clin. N. Am. 2017, 64, 381-388. [CrossRef]

29. Chu, T.B.; Liu, T.C.; Chen, C.S.; Tsai, Y.W.; Chiu, W.T. Household out-of-pocket medical expenditures and National Health Insurance in Taiwan: Income and regional inequality. BMC Health Serv. Res. 2005, 5, 60. [CrossRef]

30. Malloy, M.H. Prematurity and sudden infant death syndrome: United States 2005-2007. J. Perinatol. 2013, 33, 470-475. [CrossRef] [PubMed]

31. Reidpath, D.D.; Allotey, P. Infant mortality rate as an indicator of population health. J. Epidemiol. Community Health 2003, 57, 344-346. [CrossRef]

32. Thakrar, A.P.; Forrest, A.D.; Maltenfort, M.G.; Forrest, C.B. Child mortality in the US and 19 OECD comparator nations: A 50-year time-trend analysis. Health Aff. 2018, 37, 140-149. [CrossRef]

33. Liang, F.W.; Chou, H.C.; Chiou, S.T.; Chen, L.H.; Wu, M.H.; Lue, H.C.; Chiang, T.L.; Lu, T.H. Trends in birth weight-specific and -adjusted infant mortality rates in Taiwan between 2004 and 2011. Pediatr. Neonatol. 2018, 59, 267-273. [CrossRef]

34. Liang, F.W.; Lu, T.H.; Wu, M.H.; Lue, H.C.; Chiang, T.L.; Huang, Y.L.; Chen, L.H. International ranking of infant mortality rates: Taiwan compared with European countries. Pediatr. Neonatol. 2016, 57, 326-332. [CrossRef]

35. Department of Statistics, Ministry of Health and Welfare. The Collaboration Center for Health Information Application, Ministry of Health and Welfare. 2021. Available online: https:/ / dep.mohw.gov.tw/dos/cp-1720-7287-113.html (accessed on 20 May 2021).

36. Tzeng, I.S.; Chen, K.H.; Lee, Y.L.; Yang, W.S. Trends and age-period-cohort effects of fertility rate: Analysis of 26,224 married women in Taiwan. Int. J. Environ. Res. Public Health 2019, 16, 4952. [CrossRef] [PubMed] 
37. Chen, C.W.; Tsai, C.Y.; Sung, F.C.; Lee, Y.Y.; Lu, T.H.; Li, C.Y.; Ko, M.C. Adverse birth outcomes among pregnancies of teen mothers: Age-specific analysis of national data in Taiwan. Child. Care Health Dev. 2010, 36, 232-240. [CrossRef]

38. Wang, R.H.; Wang, H.H.; Hsu, M.T. Factors associated with adolescent pregnancy- a sample of Taiwanese female adolescents. Public Health Nurs. 2003, 20, 33-41. [CrossRef] [PubMed]

39. Xavier, C.; Benoit, A.; Brown, H.K. Teenage pregnancy and mental health beyond the postpartum period: A systematic review. J. Epidemiol. Community Health 2018, 72, 451-457. [CrossRef]

40. Cunnington, A.J. What's so bad about teenage pregnancy? J. Fam. Plann. Reprod. Health Care 2001, 27, 36-41. [CrossRef]

41. Vargas, G.; Borus, J.; Charlton, B.M. Teenage pregnancy prevention: The role of young men. Curr. Opin. Pediatr. 2017, 29, 393-398. [CrossRef] [PubMed]

42. Stanger-Hall, K.F.; Hall, D.W. Abstinence-only education and teen pregnancy rates: Why we need comprehensive sex education in the U.S. PLoS ONE 2011, 6, e24658. [CrossRef]

43. Kong, F.; Wang, A.; He, J.; Xiong, L.; Xie, D.; Su, J.; Liu, Z. Trend of unintentional suffocation death for infants under 1 year of age from 2009 to 2018 in Hunan, China: A cross-sectional study. BMJ Open 2020, 10, e038666. [CrossRef]

44. Hsin, Y.C.; Chang, Y.C.; Lee, E.P.; Chiu, C.H.; Chou, I.J.; Hsia, S.H.; Lin, K.L.; Lee, J.; Huang, J.L.; Wang, C.J.; et al. Prevention, Protection Against Child Abuse, Neglect (PCHAN) Study Group. Risk factors for child maltreatment by the utilization of medical service and socioeconomic environment in Taiwan. Medicine 2018, 97, e13728. [CrossRef] [PubMed]

45. American Academy of Pediatrics; Hymel, K.P.; Committee on Child Abuse and Neglect; National Association of Medical Examiners. Distinguishing sudden infant death syndrome from child abuse fatalities. Pediatrics 2006, 118, 421-427. [CrossRef] [PubMed]

46. Howard, L.M.; Hannam, S. Sudden infant death syndrome and psychiatric disorders. Br. J. Psychiatry 2003, 182, 379-380. [CrossRef]

47. Howard, L.M.; Kirkwood, G.; Latinovic, R. Sudden infant death syndrome and maternal depression. J. Clin. Psychiatry 2007, 68, 1279-1283. [CrossRef] [PubMed]

48. Chou, W.J. Maternal mental health and child development in Asian immigrant mothers in Taiwan. J. Formos. Med. Assoc. 2010, 109, 293-302. [CrossRef]

49. Shu, B.C.; Lung, F.W.; Chen, C.H. Mental health of female foreign spouses in transnational marriages in southern Taiwan. BMC Psychiatry 2011, 11, 4. [CrossRef] 
50. Foss, G.F.; Chantal, A.W.; Hendrickson, S. Maternal depression and anxiety and infant development: A comparison of foreign-born and native-born mothers. Public Health Nurs. 2004, 21, 237-246. [CrossRef]

51. Lee, C.H. Sudden Infant Death Syndrome in Taiwan: A comparative epidemiological survey on cases with and without forensic autopsy. Master's Thesis, Graduate Institute of Forensic Medicine, College of Medicine, National Taiwan University, Taipei, Taiwan, 2012. (In Chinese) [CrossRef]

52. Chang, Y.C.; Huang, J.L.; Hsia, S.H.; Lin, K.L.; Lee, E.P.; Chou, I.J.; Hsin, Y.C.; Lo, F.S.; Wu, C.T.; Chiu, C.H.; et al. Prevention, Protection Against Child Abuse, Neglect (PCHAN) Study Group. Child protection medical service demonstration centers in approaching child abuse and neglect in Taiwan. Medicine 2016, 95, e5218. [CrossRef] [PubMed] 